\section{AMERICAN SYMBOLISM.}

IN 1899 Mrs. Morris K. Jesup generously provided the means for a study of the Arapaho Indians, and Dr. Alfred L. Kroeber was entrusted with the work; his genera description of the Arapaho and of their decorative art and symbolism recently published in the Bulletin of the American Museum of Natural History (vol. xviii. pp. I-I 50, 1902) proves how well he acquitted himself of his task. Dr. Kroeber now has charge of the anthropological department of the University of California, and we may expect much good work from him in the future in this new field.

The Arapaho are typical Plains Indians, and belong to the linguistic stock of the western Algonkins. The fullest and most accurate account of these people has been given by Mr. James Mooney ("Ghost-Dance Religion," Fourteenth Ann. Rept. Bureau Ethnol.), and the sketch of their social organisation and life given by Dr. Kroeber is instructive, and to some extent supplements the previous descriptions.

The main value of Dr. Kroeber's memoir consists in the carefui analysis of the meaning of a very large number of designs that ornament objects in every-day use, and in the wealth of the accompanying illustrations. The conscientious labour which this implies is deserving of the thanks of fellow-students of decorative art and symbolism.

There is a good deal of latitude in the interpretation of decorative designs employed by different individuals : usually an Indian refuses to interpret the ornamentation on an article belonging to someone else, giving as a reason that he does not know what that particular artist intended to represent. For example, the rhomboid or diamond-shaped symbol may signify the navel, a person, an eye, a lake, a star, life or abundance, a turtle, a buffalo-wallow, a hill or the interior of a tent. All except the first of these significations have also been found attached to very different symbols; thus, a person is also denoted by a small rectangle, a triangle or a square, by a cross, a dot or a line, as well as by rudely realistic designs. A lake may be represented by a square, a trapezoid, a triangle, a pentagon, a circle or other figures. The decorative symbolism is not intended as a means of communication, hence there is no fixed system of symbolism. One person thinks about the significance of his designs, while another considers chiefly their appearance. The former may have two or three interpretations for one symbol or design which are appropriate and coherent; the symbols of the latter will have their most conventional meaning, without much relation to a thought-out scheme. In either case, the Indian never dreams of making a picture that can be recognised by everyone at first sight. These peculiarities can be paralleled in other parts of North America, and, indeed, elsewhere.

A pictograph serves as a means of record or communication, and is normally not decorative; while this art is too decorative to allow of its being read in the same way; yet there is considerable similarity in the symbols used in both systems. Moreover, the significance of a piece of decoration is at times as extended and coherent as that of a pictograph.

Dr. Kroeber insists that the closeness of connection between this decorative symbolism and the religious life of the Indians cannot well be overestimated by a white man. All symbolism, even when decorative and unconnected with any ceremony, tends to be to the Indian a matter of a serious and religious nature.

A. C. H. \section{THE ORIGIN OF NATURAL GAS AND
PETROLEUM.}

THE volcanic origin of natural gas and petroleum is strongly advocated by Mr. Eugene Coste in a paper read before the Canadian Mining Institute (March 5). The author points to the complete analogy of the products of the oil and gas fields with the products of volcanic solfataric action. These products are water, chloride salts, sulphur, sulphuretted hydrogen, carbonic acid and hydrocarbons. $\mathrm{He}$ brings forward facts upon which he bases his view that all the petroleum, natural gas, and bituminous fields or deposits are essentially the products of solfataric volcanic emanations, condensed and held in their passage upward in

No. J749, vOL. 68] the porous tanks (sands, limestones, \&c.) of all ages from the Archæan to the Quaternary. He instances the occurrence of carbon and hydrocarbons in gneisses and various ancient plutonic rocks. He likewise refers to the dolerite of the Lothians (described by Mr. H. M. Cadell), in which cavities of the rock are filled with a mineral wax not unlike the ozocerite of Galicia. The oil shales through which the igneous rocks have intruded were in $\mathrm{Mr}$. Coste's opinion impregnated by solfataric emanations, for their bituminous character is local, and in proximity to the igneous rocks. Allusion is made to the occurrence of asphalts and oils along the faulted and broken margins of the Gulf of Mexico and Caribbean Sea, the great asphalt deposit of Trinidad filling the crater of an extinct volcano. Again, natural gas and petroleum are associated with mud volcanoes. The author therefore concludes that carbon and hydrocarbons are derived from deep-seated fluid magmas, in which they exist probably in the form of carbides. The " rock pressure" of naturat gas is regarded as a remnant of the initial volcanic energy. This has been registered as high as $1525 \mathrm{lb}$. to the square inch, but is usually between 200 and $1000 \mathrm{lb}$., and is a constantly decreasing pressure from the time the gas is first used. The theory that artesian water is the cause of the gas pressure is regarded as untenable.

The author points out how generally the diversified "oil phenomena," which include gypsum, sulphur, dolomite, and salt, are met with in American and other oil and gas fields. Disturbed strata and planes of faulting gave access to volcanic emanations which brought up the various products : the rocks were variously impregnated according to the geological and physical conditions of the strata, and the products were sealed up when impervious unbroken strata remained above. In Galicia solid petroleum or ozocerite exists in veins cutting the strata in every direction, the most important being faults. Elsewhere oil occurs in the fractured strata, and such an elusive fluid, pent up under pressure, could not be in its original home. The local and seemingly accidental occurrence of the oil and gas, and even of bituminous shales, are considered by the author to favour his theory, for he observes that the sedimentary strata could not produce from a limited fossiliferous area the quantity of products. Thus, near Baku, in Russia, a small area of not more than eight square miles has now yielded more than 900 million barrels of oil.

H. B. W.

\section{SMITHSONIAN REPORT ON SCIENTIFIC WORK.}

DR. S. P. LANGLEY, secretary of the Smithsonian Institution, has issued his report on the operations of the Institution during the year ending June 30,1902 , including the work in the United States National Museum, the Bureau of American Ethnology, the International Exchanges, the National Zoological Park, and the Astrophysical Observatory.

Following the precedent of several years, there is given, in the body of the report, a general account of the affairs of the Institution and its bureaus, while an appendix presents more detailed statements by the persons in direct charge of the different branches of the work. Independently of this, the operations of the National Museum are fully treated in a separate volume of the Smithsonian $\mathrm{Re}$ port, and the Report of the Bureau of American Ethnology constitutes a volume prepared under the supervision of the director of that Bureau.

The following extracts from the report will show that a vast amount of scientific work is being instituted and carried on under the auspices of the Institution.

Hodgkins Fund.- In connection with the administration of the Hodgkins fund, papers recording the advance of specialists along various interesting lines of investigation have been submitted, some of which are now in course of publication.

The report of the research on the spectrum conducted by Dr. Victor Schumann, of Leipzig, has received extensive additions during the year, notably through a detailed description of the ingenious apparatus used in his work. A second grant on behalf of Dr. Schumann has been approved during the year, and it is interesting to know that 
Harvard University, recognising the value of his work, has also awarded him a grant. The new Physical Institute of the Royal Academy of Sciences in Leipzig has likewise aided this research by placing laboratory room at the disposal of Dr. Schumann, who, it is hoped, will be able in the near future to secure still more complete results from his painstaking experiments in vacuum spectroscopy.

The memoir by Dr. Carl Barus, issued as part of vol. xxix., Smithsonian Contributions to Knowledge, describes experiments with ionised air, begun by Dr. Barus some years since, and recently prosecuted under a Hodgkins grant from the Institution. The research was tributary to an investigation of the colours of cloudy, condensation. Lord Rayleigh's famous theory, if applied, would stop at the deep reds of the first order, terminating in opaque, whereas in the laboratory experiments exceptionally brilliant colours, extending almost into the third order of Newton's series, may be produced. It was thus essential as a preliminary step to investigate appropriate means for the production of nuclei, to determine their number per cubic centimetre, their velocity, their association with ionisation, the effect of the pressure of an electric field, \&c. This was the general trend of the experiments by Dr. Barus. The endeavour was made with the aid of the condensation tube to show that the nucleus has a specific velocity of its own, and that this is retained even in the absence of an electric field. The application of this principle to plate, to tubular, and to spherical condensers leads, in every case and in spite of the variation of method, to an order of values as to the number of particles in action, agreeing with the data obtained by other investigators from different experiments and theoretically different points of view. A second grant has been approved on behalf of Dr. Barus, and a new memoir on the structure of the nucleus, detailing experiments subsequent to those described in the volume just published, is soon to be submitted by him.

The experiments in air resistance by $\mathrm{Mr}$. C. Canovetti, which were begun at Brescia, Italy, have been continued and by means of an ingenious apparatus he has prosecuted a research which has been reported upon in detail, with illustrations accompanied by tables giving the numerical results attained.

Dr. von Lendenfeld, of the University of Prague, who has been assisted by a grant from the Hodgkins fund, reports that his studies are now sufficiently advanced to enable him to begin the preparation of his manuscript for publication. Telephotography has been extensively and successfully used in this research, and the summary of work already submitted is accompanied by interesting illustrations. A monograph embodying the results of the completed research, which will be published later, will present an anatomical and physiological study of insects, the lower vertebrates (Exocoetus, Draco, \&c.), birds, mammals (Petaurus, Geleopithecus, \&c.), and will treat of the polygenetic developnent of the organs of flight in animals. The physical properties of the air, wind velocities, resistance, \&c., will be considered, and it is hoped that the publication will not only prove of general interest, but will become a valuable work of reference for students.

The research into the nature of vowels by Prof. Louis Bevier, of Rutgers College, has been reported on through a series of published articles, transmitted by the author to the Institution, which record in detail the results thus far obtained. The investigation is still in progress, the vowel series from "a" to " $\mathrm{u}$ " being now under analysis and discussion.

A grant has been approved on behalf of Mr. E. C. Huffaker for the construction and practical application of a device intended to produce a uniform and measured flow of air through a tube of any desired diameter. This apparatus is primarily designed for use in connection with investi gations in the line of biology, and it has already been applied to exact experiments in the development of the embryo in the egg. It is hoped that by means of this invention facts may be established which will prove of practical value.

The meteorological investigations in connection with air currents at varying altitudes, heretofore reported on as conducted by Mr. A. L. Rotch at Blue Hill Meteorological Observatory, have been supplemented this year by a series

NO. 1749 , VOL. 68] of experiments on the lift and drift of the wind on plane and curved surfaces.

Dr. Morris W. Travers, of University College, London, has received a grant, and is now engaged in an investigation which will deal largely with the liquid properties of hydrogen.

National Museum.-This museum, established in the fundamental Act creating the Smithsonian Institution, grew up largely from its private collections, but it is important to consider that now it has grown into something which represents more nearly the large purpose of Congress in its foundation and that it is becoming a "National "Museum. It differs from most other museums in that its primary function was held to be not so much the entertainment or instruction of the resident population as the preservation and arrangement of the collections brought together by the Government of the United States. These collections now outnumber by some millions of specimens those which it has been possible to place upon exhibition in the present inadequate quarters. The number of specimens received during the year was about 450,000 , making the total number of objects nearly five and a half millions.

Bureau of American Ethnology.--The work of this Bureau has related largely to a study of the origin, physical and mental characteristics, arts and industries, food supply, social and political institutions, religions, and languages of native American tribes.

Field work was conducted in Alaska, Arizona, California and in several other States and Territories, as also in British Columbia, Mexico, Greenland, and in Porto Rico, while useful information and material was obtained from correspondents and special collaborators. Special attention was devoted to a study of those aboriginal industries which appeared to bear practical relations to modern life, particularly to aboriginal methods of house building and irrigation, and to food sources in those tropical and arid regions that formerly sustained a population five to ten times larger than at the present day. A noteworthy investigation of aboriginal industries was conducted in Porto Rico, and a special report of the native resources of that island is in preparation.

A special study was made of a ceremony among the Pawnee Indians embracing songs of interest in the development of music and poetry, and to early phases of the drama, the memoir being accompanied by the primitive music recorded by the aid of the graphophone, and with photographs of movements and objects introduced in the ceremony.

International Exchanges.-During the last fiscal year there was handled 125,796 packages, the packages sent abroad numbering 87,149 , and those received from foreign countries 38,647 . The number of parcels exchanged with Germany was 20,679, and with Great Britain 19,912. France comes next with 11,378 , and then Mexico, Italy, Austria-Hungary, and Russia.

It has long seemed desirable to establish more adequate exchange relations with Japan and China, but efforts in that direction have so far been without success. In Great Britain, Germany, and Austria-Hungary, it is still necessary to employ salaried agents to carry on the work, the Governments of these countries for various reasons nct yet having organised international exchange bureaus.

Five years ago, in 1897 , the total number of correspondents or participants in the exchange service was 28,008 , while the aggregate has now reached 38,200 addresses of libraries and individuals in $\mathrm{r}_{54}$ countries scattered all over the civilised world, even in some of the remotest corners of India, Asia, Australia, and Polynesia.

The general benefit of the service to the scientific world can hardly be measured. Largely as a result of these international exchanges there has accumulated in the Library of U.S. Congress a mass of scientific and Government publications that is probably not surpassed anywhere, and could scarcely have been secured in any other way.

National Zoological Park.-Dr. Langley has in previous years called the attention of the Regents to the want of a grant for collecting and preserving some of the great land and marine specimens of the Western territory now rapidly approaching extinction, and he again urges the immediate need of doing something, even on the smallest scale, before it is entirely too late. It is hoped that means will be provided to meet these wants by the establishment of at least 
two small stations or ranches in Alaska, one in the interior, where may be secured specimens of the great moose, the great bear, and other disappearing animals of the land fauna; the other "ranch" to be on the coast for the collection of the walrus, the sea otter, the great sea lion of Steller, and other important vanishing marine species.

The animals in the National Zoological Park at the close of the fiscal year included 506 mammals, 232 birds, and 145 reptiles. The accessions of the year numbered 314. More than half of these accessions were gifts to the Government, several of the most interesting animals having been secured through the cooperation of United States consuls and other officials. A fine specimen of grizzly bear, also some antelope, deer, elk, and cinnamon bears were received from the Yellowstone National Park.

The native game, formerly everywhere plentiful, has grown so nearly inaccessible that only after years of effort have there at last been procured a single young male specimen of the great Kodiak bear and two big horn or Rocky Mountain sheep.

The Astrophysical Observatory.-The principal work of the Astrophysical Observatory during the past year has continued to be the study of the sun and its radiation. While fully acknowledging the interesting nature of astrophysical investigation of the stars and nebulæ, the study of the sun has a far superior practical importance, for were the former bodies to be wholly blotted out, they would be missed chiefly as objects of scientific interest, while with the sun would be abolished life itself. The solar researches have mainly been concerned with determining the amount and nature of the absorption of solar radiation in the earth's atmosphere and in the solar envelope. These researches are preliminary to, and form an essential part of, the measurement of the total radiation of the sun. A presumption exists, almost amounting to certainty, that the total radiation of the sun is variable in some relation to the appearance of sun-spots, but nothing is yet known to fix definitely the amount of this supposed variability or to measure its effect upon the earth, though that effect, if so fixed, cannot but be of interest to every inhabitant of the earth's surface.

The instrumental means, which thus have been the subject of incessant study and improvement here during the past len years, for investigating such questions, are more efficient than at any previous time. The detailed report shows that automatic bolometric curves accurately representative of the amount and distribution of the solar energy at the observer's station may now be obtained in a few minutes, covering nearly the whole spectral region which reaches sea level, and where occurs much of the great and varying absorption by water vapour which influences our terrestrial temperatuies so greatly.

Some twenty years ago, when Dr. Langley invented his " bolometer," the instrument was able to measure temperature to about one one-hundred-thousandth of a degree. Since then, during fifteen years of constant advance, latterly associated with a great improvement of the adjuncts, particularly of the galvanometer, at the hands of Mr. C. G. Abbot, this has been brought to measure somewhat less than one-hundred-millionth of a degree, and this almost infinitesimal amount is distinguished with readiness and precision. It is this increased precision which is associated with all the improvements in the work of the year here described.

It is the variability of the absorption of our air which now offers the greatest difficulty to the work. Dr. Langley cherishes the hope that a solar observatory will one day be established high in a clear and dry air, the chief aim of which shall be to solve the questions of the amount of radiation of the sun, the changes in this total amount, and the consequences of such changes on the earth.

The interest of this solar study is peculiar among all the subjects of astronomical research, for it is not only a scientific but a utilitarian interest of such high importance that it has among its remote possibilities the forecasting of the coming seasons and harvests, and of conditions immediately practical, from those which affect the price of the labourer's dinner up to those which, to use the weighty words of Prof. Newcomb, may bring to light not merely interesting cosmical processes, but " cosmical processes pregnant with the destiny of our race."

NO. I 749 , VOL. 68]

\section{UNIVERSITY AND EDUCATIONAL INTELLIGENCE.}

CAMBridge.-The General Board of Studies report that in their opinion it is expedient to reestablish the chair of surgerv, which has been suspended since Sir George Humphry's death. They propose a stipend of $600 l$. a year, with freedom to undertake private practice, and the right to be ex officio surgeon to the hospital and to hold a college fellowship.

A special syndicate has been appointed to consider arrangements for the future conduct of the engineering department, in view of the approaching departure of Prof. Ewing. A bust of the late Dr. John Hopkinson has been presented to the Hopkinson Laboratory, and will be unveiled during the present term.

THE second reading of the London Education Bill was carried in the House of Commons on April 29 by 300 votes to 163 .

At a meeting of the Court of Governors of University College, Liverpool, held on May 2, the chairman alluded to the endowment of a chair of electrotechnics, for which special purpose a donation of $10,000 l$. had been made by Mr. Jardine, and stated that they hoped to receive other special donations in order to establish professorships of applied mechanics and applied mathematics. A new building for electrotechnics and biology is to be erected, which it is hoped will be one of the most perfect of the kind in the country. It was also announced that, assuming all went well, and that the charter constituting the Liverpool University College a separate university was granted in June or early in July, the necessary Act of Parliament would probably be passed during the present session.

THE annual conference of the presidents, deans and executive officers of many of the institutions for the higher education of women in the United States was held this year at Snith College on April I8. The association, which numbers among its nembers eleven colleges for women and co-educational institutions, as well as associations and individuals, maintains a table at the Zoological Station at Naples, awarding places at it to from one to five persons each year. A place at the American Women's Table at this Station for $1903-4$ was awarded to Dr. Grace Emily Cooley, associate professor of botany at Wellesley College, who will thus become scholar of the association. An additional award has, however, been made this year, that of the prize of $200 l$. offered two years ago for the best piece of scientific research work done by a woman. Twelve professors representing the biologica!, chemical, and physiological sciences act as board of examiners for the association. This year they considered eleven scientific investigations, and awarded the prize to Dr. Florence R. Sabin, assistant in anatomy at the Johns Hopkins University Medical School, for the results of an investigation on the origin of the lymphatic system. Honourable mention was given to the paper on the lifehistory of Pinus by Miss Margaret Ferguson. The prize of $200 l$. is again offered, to be awarded in 1905 .

\section{SOCIETIES AND ACADEMIES.}

LONDON.

Physical Society, April 24.-Mr. T. H. Blakesley, vice-president, in the chair.-Mr. W. B. Crost exhibited several novel and ingenious pieces of physical apparatus.Dimensional analysis of physical quantities and the correlation of units, by Mr. A. F. Ravenshear. The object of this paper is to knit together various divergent views which are current on the subject of dimensions. It is shown that while (I) dimensional analysis and the correlation of units of different kinds can be pursued in one direction until, with completed correlation, we arrive at degrees of undifferentiated quantity, a different procedure may be followed which (2) gives rise to various systems of dimensions descriptive of the physical relationships of the quantities treated. The conditions giving rise to dimensional relations are first set out, and it is proposed to distinguisin the purely quantita- 